\title{
Effects of Variety and Fermentation Time on the Quality of Rice Wine
}

\author{
Henock Woldemichael Woldemariam ${ }^{{ }^{\star}}$, Hilegebreal Alamrewu Aklilu ${ }^{2}$, \\ Hileyesus Regasa Dire ${ }^{3}$ and Gebrehana Girma Shikur ${ }^{4}$
}

\author{
${ }^{1}$ School of Chemical and Food Engineering, Bahir Dar Institute of Technology, Bahir Dar University, \\ Post Box No: 26, Bahir Dar, Ethiopia. \\ ${ }^{2}$ BGI Ethiopia, Hawassa Branch, Post Box No: 2024, Hawassa, Ethiopia \\ ${ }^{3}$ Kaliti Food S.C., Post Box No: 1819/3921, Addis Ababa, Ethiopia \\ ${ }^{4}$ Ethiopian Conformity Assessment Enterprise, Post Box No: 11145, Addis Ababa, Ethiopia
}

\begin{tabular}{|c|c|}
\hline Abstract & Fle III \\
\hline \multirow{3}{*}{$\begin{array}{l}\text { A study was conducted to investigate the effect of variety and fermentation time on rice wine } \\
\text { quality. Two rice varieties, } X \text { - Jigna and Gomera, and three fermentation times, } 5,6 \text { and } 7 \\
\text { days were used to study the physicochemical and sensory qualities of wine. Significant } \\
\text { difference was observed at } P<0.05 \text { among the rice varieties with respect to different wine } \\
\text { quality parameters and maximum pH (4.98), total soluble solids }(3.83 \text { Brix) and overall } \\
\text { sensory acceptance }(4.32) \text { were recorded for rice wine prepared from } X \text { - Jigna with } 5 \text { days of } \\
\text { fermentation time. Wine prepared from Gomera variety for } 7 \text { days of fermentation time } \\
\text { recorded the highest alcohol content }(15.47 \%) \text { followed by } X \text { - Jigna variety with the same } \\
\text { days of fermentation time }(14.90 \%) \text {. In comparison, the wine from Gomera rice variety with } 6 \\
\text { days of fermentation time was found the least overall acceptance }(3.84) \text {. Rice wine could, } \\
\text { therefore, be produced for immediate consumption as a value added product and future } \\
\text { research is still required to determine the potential of other rice varieties, the effect of other } \\
\text { factors and the shelf life stability of the rice wine. }\end{array}$} & $\begin{array}{l}\text { le History } \\
\text { eived : } 18 \\
\text { ised }: 20 \\
\text { epted }: 23\end{array}$ \\
\hline & $\begin{array}{l}X \text { - Jigna and Gomera } \\
{ }^{*} \text { Correspondina Author: }\end{array}$ \\
\hline & k Woldemichael \\
\hline & \\
\hline
\end{tabular}

\section{INTRODUCTION}

Rice (Oryza sativa L.) is one of the leading food crops of the world and is second only to wheat in terms of annual production for food use. It is the main staple food for about the $60 \%$ of the world's population. Rice is predominantly an Asian crop, $95 \%$ of it is being produced and consumed in the south East Asian countries extending from Indo-Pakistan sub-continent to Japan (Wadhai and Gondane, 2003). In industrial usage, rice is gaining importance in the making of infant foods, snack foods, breakfast cereals, beer, fermented products, rice bran oil and rice wine (Jaheo et.al., 2003).

Wine making from grape and other fruits is an age old practice but exploring the possibility of wine making from rice is yet to be achieved. Rice, barley, corn, wheat and sorghum are the main cereals used for preparation of alcoholic beverages. Rice wine is an alcoholic beverage made from rice. Unlike European wine, which is made by fermentation of naturally sweet grapes and other fruit, rice wine is made from the fermentation of rice starch converted to sugars. This process is akin to that used to produce beer. However, beer production employs a mashing process to convert starch to sugars, whereas rice wine uses the amylolytic process by the action of acids or enzymes like amylase (Subhasree, 2010).

In Ethiopia, rice is compatible for various traditional food recipes like bread, soup, "enjera", and local alcoholic beverages like "tela" and "areki". The country has also a comparative advantage of producing rice due to the availability of huge and cheap rural labor as the crop is labor intensive. The importance of rice as a food security crop, source of income and employment opportunity due to its relative high productivity as compared to other cereals is recognized by farmers as well as private investors who frequently request for improved varieties for different ecosystems. Besides, rice is one of the highly adaptable crops that are used as a food in the form of solid and liquid. However, production of homemade wine from this raw material is unusual. Studies on the effect of variety and fermentation time on the production of wine will help to generate information on rice wine quality. Thus, the present investigation was taken up to identify suitable rice variety and optimum fermentation time to produce rice wine that has good physicochemical and sensory qualities. 


\section{MATERIALS AND METHODS}

\section{Study Area}

The study was carried out at Food Process and Food Analysis Laboratories, School of Chemical and Food Engineering, Bahir Dar Institute of Technology, Ethiopia.

\section{Sample Collection}

Two rice varieties, $X$ - Jigna and Gomera, were obtained from Woreta Agricultural Research Institute, yeast and barley malt were collected from Gondar Dashen Brewery.

\section{Experimental Design}

The experiment was designed with a $2 \times 3$ factorial design comprising two rice varieties treated at three different fermentation times and was laid out in a Completely Randomized Design (CRD) with three replications.

\section{Production of Rice Wine \\ Washing and Steeping of Rice}

The rice was washed repeatedly until the drained water become clear (Figure 1). During washing, the grains are subjected to a kind of polishing caused mainly from collision of the grains in water. This process removes some of the surface parts of the grains (1 to $2 \%$ of the total grain weight). During washing, the grains absorb some amount of water. Washed rice grains are steeped in water immediately for 2 days. After this procedure, the grains absorb water to about 25 to $30 \%$ of their weights, which promotes penetration of heat into the grains during steaming (Adams, 2008).

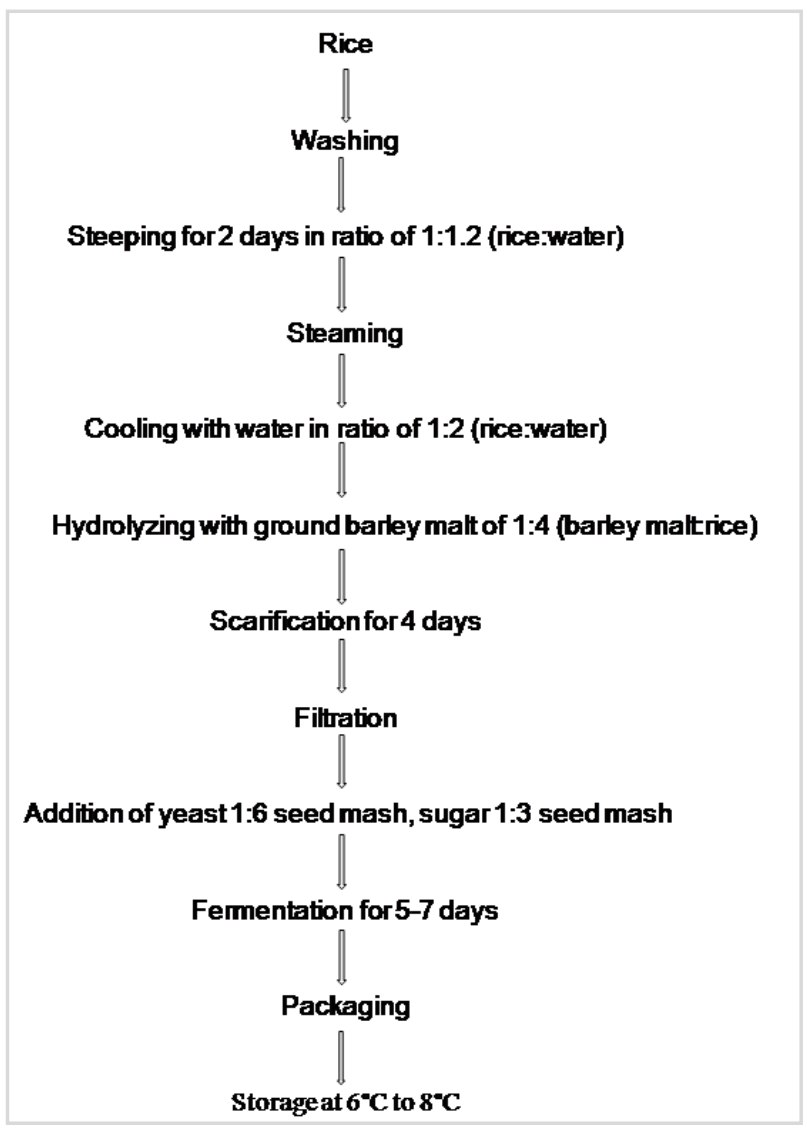

Figure 1: General flow chart of rice wine production
Sci. Technol. Arts Res. J., July-Sep 2014, 3(3): 44-47

\section{Steaming of Rice}

The drained rice is transferred to the side of a steamer, the rice being steamed lasts for 20 minutes, during which some water was poured to the steamed rice. In this way, the steamed rice becomes softer. Steaming of rice is important to gelatinize the starch contained in rice kernel by the effect of water vapor penetrated into it. During the course of steaming, the crystal structure of rice starch is destroyed and becomes $\alpha$-type, which favors the growth of yeasts. The gelatinized starch can easily be hydrolyzed by amylase or glucoamylase (Hsing-Tsung, 2000).

\section{Cooling of the Steamed Rice}

The rice was cooled by flowing cold water through the hot rice (drenching). In this method, the steamed rice was scooped into a bamboo basket with a screen mounted beneath the bottom.

\section{Preparation of Seed Mash}

The seed mash for rice wine was prepared by addition of ground barley malt which contains hydrolyzing enzymes (Subhasree, 2010).

\section{Scarification and Fermentation}

Scarification of the seed mash lasts for 4 days and then the young seed mash was filtered and poured into fermenter with narrow neck for fermentation. Yeast was added in the ratio of 1:6 (yeast:seed mash) to initiate the fermentation process (Hsing-Tsung, 2000 and Adams, 2008).

\section{Post-fermentation Treatments}

Separation of Spent Grains: Since the rice wine mash is very dense and mushy, it was very difficult to obtain the liquid part (rice wine) by filtration or sedimentation. Combination of filtration and squeezing provided effective approach for separating the liquid from the mash. The slightly turbid rice wine passed through series of filters for clarification and packed with bottles for quality analysis.

\section{Physiochemical Analysis}

pH: $\mathrm{pH}$ of the samples was recorded by using $\mathrm{pH}$ meter. Standard solutions of $\mathrm{pH} 4.0$ and 7.0 were used as reference to calibrate.

Total Titrable Acidity (TTA): Five $\mathrm{ml}$ of the sample was taken in $50 \mathrm{ml}$ volumetric flask and volume was made up. From this, $5 \mathrm{ml}$ of aliquot was taken in a $50 \mathrm{ml}$ conical flask and titrated against $0.1 \mathrm{~N}$ sodium hydroxide solution using two drops of phenolphthalein indicator (Subhasree, 2010).

Total Soluble Solids (TSS): Brix reading of the wine samples were determined with the help of digital refractometer having a range of $0-32^{\circ}$ Brix at $20^{\circ} \mathrm{C}$.

Alcohol Content: Rice wine sample $(100 \mathrm{ml})$ was poured in to the $100 \mathrm{ml}$ of volumetric flask. The samples were distillated until $25 \mathrm{ml}$ of distillate is collected. The volume of distillate was restored to $100 \mathrm{ml}$ with distilled water. Then the specific gravity was measured by using hydrometer and recorded the corresponding alcohol percentage volume (Kim et al., 2013).

Sensory Evaluation: Sensory evaluation of rice wine samples was estimated by ten consumer sensory 
Henock Woldemichael et al.,

panelists. Sensory parameters which includes flavor, color, mouth feel, sweetness, appearance and overall acceptance of rice wine were evaluated using a Hedonic scale of 1 to 5 , where 5 being "excellent" and 1 "poor".

\section{Data Analysis}

Triplicate data were subjected to ANOVA using JMP version 5 statistical software (SAS, 2003). Means were compared using Student's test at $P<0.05$.

\section{RESULTS AND DISCUSSION}

\section{Physicochemical Analysis of Rice Wine}

The observations recorded on physicochemical analysis of wine prepared from different rice varieties clearly indicated that there was significant difference in the rice varieties with respect to $\mathrm{pH}$ (Table 1). Maximum $\mathrm{pH}$ (4.98) was recorded for rice wine prepared from $X$ Jigna with five days of fermentation but lowest in total titratable acidity among wines with 6 and 7 days of fermentation time. On the other hand, wine obtained from Gomera rice variety with five days fermentation time was also the highest in $\mathrm{pH}$ but showed lowest total titratable acidity. Kim et al., 2013 also obtained a $\mathrm{pH}$ value of 4.4 for the 6 day fermentation period of rice wine which is slightly less than the present study. Generally, $\mathrm{pH}$ of the wines depends on the acid and sugar content of the wines.

Citric, malic and tartaric acids are important acids present in wine that measure the total titrable acidity of wine samples. Results indicated that highest titrable acidity (12.92\%) was observed for rice wine from $X$ - Jigna rice variety for 7 days of fermentation time and wine from
Sci. Technol. Arts Res. J., July-Sep 2014, 3(3): 44-47

Gomera rice variety with 5 days of fermentation time showed the least total titratable acidity $(9.29 \%)$.

Significant difference was observed for total soluble solids of wines prepared from $X$ - Jigna rice variety with 5 days of fermentation time which had maximum total soluble solids (3.83 ${ }^{\circ}$ Brix) and least total soluble solids (2.77 ${ }^{\circ}$ Brix) was observed with the wine from the same Gomera rice variety with 7 days of fermentation time. This might be due to the difference in reducing sugar content in the rice varieties and reducing sugars constitute a major part of soluble solids present in the must. Similar work was done by (Kyalakond, unpublished results) who reported that rice wine prepared from the different rice varieties had TSS of 3.0 to $3.9{ }^{\circ}$ Brix where most of the study results fall in the range.

Alcohol is an important parameter to measure wine quality. In this study, wine prepared from Gomera variety for 7 days of fermentation time recorded the highest alcohol content (15.47\%) followed by $X$ - Jigna variety with the same days of fermentation time (14.90\%). These results are in line with Dung, 2013 who stated the alcohol content of rice wine may reach up to $15 \%$ depending on the fermentation performance. Wine from $X$ - Jigna variety with 5 days of fermentation time revealed lowest alcohol content $(13.63 \%)$. This could be due to the reason that amount of alcohol produced depends on the variation in fermentable sugar, fermentation efficiency of yeast, capacity of sugar uptake and alcohol tolerance limit. Thus, alcohol content is one of the factors that affect the quality of rice wine and can be used to show the degree of fermentation throughout the fermentation process.

Table 1: Effects of variety and fermentation time on physicochemical qualities of rice wines

\begin{tabular}{cccccc}
\hline Samples & $\begin{array}{c}\text { Fermentation } \\
\text { time (Days) }\end{array}$ & pH & $\begin{array}{c}\text { Total Titratable } \\
\text { Acidity \% (TTA) }\end{array}$ & $\begin{array}{c}\text { Total Soluble Solids } \\
\text { in Brix (TSS) }\end{array}$ & $\begin{array}{c}\text { Alcohol } \\
\text { Content in \% }\end{array}$ \\
\hline \multirow{3}{*}{ X-Jigna } & 5 & $4.98^{\mathrm{a}} \pm 0.03$ & $12.62^{\mathrm{a}} \pm 1.31$ & $3.83^{\mathrm{a}} \pm 0.15$ & $13.63^{\mathrm{a}} \pm 0.91$ \\
& 6 & $4.94^{\mathrm{ab}} \pm 0.03$ & $12.70^{\mathrm{a}} \pm 0.84$ & $3.73^{\mathrm{a}} \pm 0.16$ & $14.47^{\mathrm{b}} \pm 0.75$ \\
& 7 & $4.92^{\mathrm{bc}} \pm 0.01$ & $12.92^{\mathrm{ab}} \pm 1.32$ & $2.77^{\mathrm{c}} \pm 0.32$ & $14.90^{\mathrm{b}} \pm 1.4$ \\
\hline \multirow{3}{*}{ Gomera } & 5 & $4.87^{\mathrm{cd}} \pm 0.01$ & $9.29^{\mathrm{b}} \pm 2.52$ & $3.63^{\mathrm{b}} \pm 0.15$ & $13.67^{\mathrm{a}} \pm 1.11$ \\
& 6 & $4.84^{\mathrm{d}} \pm 0.01$ & $10.09^{\mathrm{ab}} \pm 0.47$ & $3.47^{\mathrm{b}} \pm 0.55$ & $14.10^{\mathrm{a}} \pm 1.44$ \\
& 7 & $4.82^{\mathrm{d}} \pm 0.04$ & $11.48^{\mathrm{ab}} \pm 1.29$ & $3.03^{\mathrm{bc}} \pm 0.15$ & $15.47^{\mathrm{c}} \pm 0.76$ \\
\hline
\end{tabular}

*Mean values not connected by same letter in a column are significantly different at $P<0.05$.

Superscripts indicate statistical significance.

\section{Sensory Evaluation of Rice Wine}

Results revealed that wine from $X$ - Jigna variety with 5 days of fermentation time showed significant difference at $P<0.05$ with maximum overall acceptance (4.32) (Table $2)$. In comparison, the wine from Gomera rice variety with six days of fermentation time was found the least overall acceptance (3.84). As a result, wine from $X$ - Jigna variety with 5 days of fermentation time was superior in the sensory characteristics of flavor, mouth feel, color, appearance, sweetness and overall acceptance.

Table 2: Effects of variety and fermentation time on sensory qualities of rice wines.

\begin{tabular}{|c|c|c|c|c|c|c|}
\hline \multirow[b]{2}{*}{ Sensory Quality Parameters } & \multicolumn{6}{|c|}{ Treatment Combinations } \\
\hline & 5 days & $\begin{array}{c}X \text { X-Jigna } \\
6 \text { days }\end{array}$ & 7 days & 5 days & $\begin{array}{c}\text { Gomera } \\
6 \text { days }\end{array}$ & 7 days \\
\hline Flavor & $4.2^{\mathrm{bc}}$ & $4.2^{\mathrm{bc}}$ & $4.2^{\mathrm{bc}}$ & $4^{\mathrm{b}}$ & $3.4^{\mathrm{a}}$ & $4.2^{\mathrm{bc}}$ \\
\hline Mouth feel & $4.6^{d}$ & $4.2^{\mathrm{bc}}$ & $4.0^{b}$ & $4.6^{d}$ & $4.0^{b}$ & $4.2^{\mathrm{bc}}$ \\
\hline Color & $4.4^{\mathrm{cd}}$ & $3.8^{\mathrm{ab}}$ & $3.6^{\mathrm{a}}$ & $3.6^{\mathrm{a}}$ & $3.8^{\mathrm{a}}$ & $3.8^{\mathrm{a}}$ \\
\hline Appearance & $4.2^{\mathrm{bc}}$ & $4.0^{b}$ & $3.6^{\mathrm{a}}$ & $3.8^{\mathrm{a}}$ & $4.0^{b}$ & $3.6^{\mathrm{a}}$ \\
\hline Sweetness & $4.2^{\mathrm{bc}}$ & $4.2^{\mathrm{bc}}$ & $4.0^{b}$ & $3.8^{\mathrm{a}}$ & $4.0^{b}$ & $4.2^{\mathrm{bc}}$ \\
\hline Overall acceptance & $4.32^{\mathrm{C}}$ & $4.1^{b}$ & $3.88^{\mathrm{ab}}$ & $3.96^{\mathrm{b}}$ & $3.84^{\mathrm{a}}$ & $4.0^{b}$ \\
\hline
\end{tabular}

*Mean values not connected by same letter in a raw are significantly different at $P<0.05$.

Superscripts indicate statistical significance. 


\section{CONCLUSIONS}

Alcoholic beverages have played an important role in human spiritual and cultural life. Alcoholic beverages are produced primarily from fruit; like grapes but also produced from cereals; especially rice that serve an important source of nutrients. When compared to fruit wine preparation, rice wine preparation has an additional step i.e., scarification of starch to simple sugars. From the present study, the results on screening of suitable rice variety and fermentation time, $X$-Jigna rice variety with 5 days of fermentation time is suitable for wine production with overall acceptable sensory qualities than Gomera rice variety. Seven days of fermentation time has preferable alcohol content $(15.47 \%)$ of the rice wine prepared from Gomera variety than five days and six days of fermentation times. As a result of the present study, it can be concluded that rice wine quality differs with rice varieties and fermentation time and significant differences were observed at $P<0.05$ with respect to various parameters like $\mathrm{pH}$, titratable acidity, total soluble solids, alcohol contents and overall sensory acceptance.

Nowadays, the development of small-scale technology to process agricultural products by fermentation is one of the major parts to improve the socio-economic situation in Ethiopia. Home-scale production units are convenient for trialing new procedures and expanded marketing would benefit the private sectors and small-scale rice wine producers. Stimulating innovation for controlled manufacture of value added products like fermented rice wine to achieve consistent good quality and high yields, the essentially important factors to be considered in the future line of works include starter inoculation, fermentation conditions, screening of various other rice varieties, shelf life and alternate processing methods.

\section{ACKNOWLEDGMENTS}

The authors are grateful to the School of Chemical and Food Engineering, Woreta Agricultural Research Institute and Gondar Dashen Brewery Industry for providing financial support, rice varieties and yeast respectively.

\section{REFERENCES}

Adams, M.R. and Moss, M.O. (2008). Food microbiology. $3^{\text {rd }}$ Edition, Royal Society of Chemistry, pp: 367. ISBN: 9780-85404-284-5 and DOI:10.1039/9781847557940

Dung, N.T.P. (2013). Vietnamese rice-based alcoholic beverages. International Food Research Journal 20(3): 1035-1041.

Hsing-Tsung, H. (2000). Science and civilization in China: Biology and biological technology. Cambridge University Press, pp: 150

Jaheo, H., Ziolko, T. and Kheradmandan S. (2003). The determination of key quality parameters in Rice using FTNIR Spectroscopy. best@buchi NIR 31.

Kim, E., Chang, Y.H., Ko, J.Y. and Jeong, Y. (2013). Physicochemical and Microbial Properties of the Korean Traditional Rice Wine, Makgeolli, Supplemented with Banana during Fermentation, Preventive Nutrition and Food Science 18(3): 203-209.

Kyalakond, A. (Unpublished Results). Studies on preparation of rice wine. Thesis submitted to the University of Agricultural Sciences, Dharwad In partial fulfillment of the requirements for the Degree of Master of Science in Agricultural Microbiology. Department of agricultural microbiology college of agriculture, Dharwad University of agricultural sciences, Dharwad - 580005.

Statistical Analysis System (SAS) Institute (2003). 'John's Macintosh Program (JMP)', version 5.0, SAS Institute Inc., Cary, NC, USA.

Subhasree, R.S. (2010). A cheap, consumable and Healthy Fermented Drink from Rice - A Review. World Journal of Dairy and Food Sciences 5 (2): 218-220.

Wadhai, V. and Gondane, M. (2003). Studies on Production of Native Wine from Rice. Journal of Research in Science and Technology 1(3):13-17. 